\title{
O ANTROPOCENO E A ANTROPO-CENA PÓS-HUMANA: NARRATIVAS DE CATÁSTROFE E CONTAMINAÇÃO
}

\begin{abstract}
Universidade Federal Fluminense/CNPq
\section{Resumo}

Um número crescente de pesquisas sobre o humano tem tido a atenção voltada para trabalhos na área biotecnológica, em busca de uma compreensão contemporânea dos atributos humanos, tradicionalmente associados ao abstrato, ao filosófico. Não obstante seu emprego predominante e indiscutível imbricamento na área da geologia, o termo "antropoceno", por sua vez, vem sendo usado com cada vez mais frequência por pesquisadores e profissionais das mais variadas áreas para destacar como a humanidade está mudando nosso planeta. Ao convocar o conceito de antropoceno para este trabalho, meu intuito é de sinalizar o momento não somente geológico mas histórico e cultural. A realidade subjacente ao conceito lança a humanidade em uma seara de incerteza tanto científica quanto discursiva. Com isso em mente, propõe-se discutir a cena humana (a antropo-cena) a partir da ficção especulativa, levando em conta o papel da linguagem e da representação na construção do (pós)humano, frente ao desastre, ao biopoder e à biopolítica.
\end{abstract}

Sonia Torres

Rio de Janeiro, BR

Palavras-chave: Ficção Especulativa; Antropoceno; Pós-humano; Biopoder; Biopolítica

\section{THE ANTHROPOCENE AND THE POSTHUMAN ANTHROPO-SCENE: NARRATIVES OF CATASTROPHE AND CONTAMINATION}

\begin{abstract}
A growing body of research on the Human focuses on work being developed in the field if Biotechnology, in search of an understanding of contemporary human attributes traditionally associated with the abstract, with the philosophical. Notwithstanding its predominant employment and undisputed imbrication in the field of Geology, the concept of the Anthropocene, in its turn, is being increasingly used by researchers and professionals from a variety of fields to underscore how humanity is changing our planet. By deploying the concept, I wish to signal both the geological and the historical and cultural moment being experienced by humanity. The underlying reality behind the concept of the Athropocene leads us into both scientific and discursive uncertainty. With this in mind, this work proposes to discuss the human scene (the 'anthropo-scene') as represented in speculative fiction, taking into account the role of language and representation in the construction of the (post)human visà-vis disaster, biopower and biopolitics.
\end{abstract}

Keywords: Speculative Fiction; Anthropocene; Post-human; Biopower; Biopolitics

"Professora Titular aposentada do instituto de letras da UFF, atua no programa de Pós-graduação em Estudos de Literatura. Pesquisa na área de literaturas de língua inglesa; literatura comparada; multidisciplinar com bolsa de produtividade em pesquisa do CNPq. Seu e-mail é sonia_torres@id.uff.br 
Vivemos num mundo confuso e confusamente percebido. Milton Santos (2011, p.9)

For the first time, we as human beings collectively constitute ourselves and, hence, are responsible for ourselves.

Michael Geyer e Charles Bright (1995, p. 1059)

The disaster, unexperienced. It is what escapes the very possibility of experience - it is the limit of writing. This must be repeated: the disaster de-scribes. Maurice Blanchot (1995, p. 7)

Oficialmente, estamos no período interglacia ${ }^{1}$ que se seguiu à última Idade do Gelo - a idade chamada Holoceno.1 Contudo, em 2002, o vencedor do Prêmio Nobel em química, Paul Crutzen, sugeriu que o planeta havia entrado em uma nova era, o Antropoceno ${ }^{2}$, por conta dos efeitos ambientais resultantes do crescimento da população humana e do desenvolvimento econômico, e o termo vem sendo empregado informalmente por vários geólogos, para denotar o ambiente global contemporâneo, dominado pela atividade humana (cf. ZALASIEWICZ, 2008, p. 4). Por conta disso, recentemente, a União Internacional de Ciências Geológicas (IUGS) determinou que a Comissão Internacional de Estratigrafia (ICS) criasse um grupo de trabalho (o WGA- Working Group on the Anthropocene) para discutir os efeitos referidos por Crutzen e, aplicando os mesmos critérios usados para estabelecer novas eras, avaliar se, de fato, justifica-se a necessidade de estabelecer o novo termo para denominar uma suposta nova idade geológica. (cf. ZALASIEWICZ, 2008, p. 4). Uma proposta sobre o assunto foi votada, em agosto de 2016 deste ano, durante o Congresso Internacional de Geologia, realizado na África do Sul. Entre os 35 cientistas do WGA, trinta votaram a favor, três contra e houve duas abstenções. Agora o grupo terá cerca de três anos para determinar quais seriam os sinais mais fortes que determinam a nova era geológica (cf. CARRINGTON, 2016). Para Jan Zalasiewicz, professor da Universidade de Leicester, no Reino Unido, presidente do grupo de trabalho da ICS e um dos coautores da revisão, "há uma realidade subjacente ao conceito do Antropoceno" -
[...] as marcas deixadas pela ação humana na Terra são tantas, tão espalhadas e tão profundas que a definição do Antropoceno seria "inequívoca". Entre elas, por exemplo, estão os chamados "tecnofósseis", como os resíduos de plástico, concreto, alumínio elemental e outros materiais artificiais que acabaram nos depósitos sedimentares do planeta e nos oceanos. Outros registros importantes apontados [pelo grupo de trabalho] são a fuligem $e$ as cinzas da queima de combustíveis fósseis que também encontraram lugar nestes sedimentos, além de se acumularem no gelo das regiões polares a partir do século XVII. (ZALASIEWICZ, apud BAIMA, 2016, $s / p)^{3}$

Podemos, resumidamente, considerar os fatores listados acima. Mas há muitos outros setores que vêm sofrendo o impacto da atividade humana, em escala global, assim como na atmosfera. O termo antropoceno vem sendo usado com cada vez mais frequência por pesquisadores e profissionais das mais variadas áreas ${ }^{4}$ para destacar como a humanidade está mudando nosso planeta. $\mathrm{O}$ impacto previsto implicará esforços de adaptação por parte da humanidade, por conta de emissões de gases e hiperaquecimento global e forças geofísicas e biológicas que fugirão ao controle humano. Secas, ciclones tropicais, ondas de calor, colheitas perdidas, enchentes, incêndios florestais e erosões são alguns exemplos extremos, com consequências extremas, como fornecimento insuficiente de água, má-nutrição e doenças infecciosas. Esses fenômenos levarão, por sua vez, à migração massiva e conflitos regionais cada vez mais intensos.

Não é apenas a geologia que está em um estado de perturbação. $\mathrm{O}$ conceito de antropoceno serve para designar um momento histórico mundial: tudo que é construído pelos humanos e que interfere nos sistemas naturais, engloba, em grande medida, as mudanças paradigmáticas que estamos testemunhando nas áreas de inteligência artificial, neurociência, biologia e biotecnologia, entre outras, e nos lança em uma seara de incerteza tanto científica quanto discursiva. Por conta da intercontaminação natureza-cultura, a humanidade será levada a defrontar-se com novas consequências organizacionais que urgem repensar o que vou chamar aqui (talvez não muito acuradamente) de "princípios 
holocênicos". Justifica-se, portanto, o emprego do conceito para sinalizar o momento não somente geológico do planeta (não obstante seu emprego predominante e indiscutível imbricamento na área da geologia) mas histórico e cultural da humanidade - a realidade subjacente ao conceito, para tomar emprestadas as palavras de Zalasiewicz, citadas acima, e reforçadas pelas oportunas observações de Latour:

The 'anthropos' that is pushed center stage by geologists is not the same passive entity that used to populate the older narrative full of 'natural' causal agents. It is a being that is inevitably endowed with moral and political history. (LATOUR, 2014, 139-AAA 4)

How could you "naturalize" anything anyway when the very ingredients of what used to play the role of "natural forces" have been so transmogrified that they include humans in pieces and morsels at every junction? All field studies are studying devastated sites in crisis. To be on planet Earth at the time of the Anthropocene is not the same thing as being "in nature" at the time of its modernization. (LATOUR, 2014, 139-AAA 12)

É interessante notar como a desconstrução de Latour do "princípio holocênico" de que nós, humanos, nada podemos contra as forças da natureza, remete, indiretamente, para movimentos literários miméticos, como o realismo e, em especial, o naturalismo, na literatura e nas artes - que propunham um olhar cientificista do mundo. E é a partir dessa constatação que eu gostaria de iniciar minhas considerações, traçando um paralelo entre a argumentação de Latour de que a própria ideia de antropoceno coloca a atuação humana (human agen$c y$ ) no centro de nossas atenções e a sugestão de que o olhar "científico" encontrado, contemporaneamente, em obras de ficção científica ou especulativa, já não se propõe impessoal, como na tradição realista, uma vez que essas obras tematizam, em enorme medida, questões de atuação humana.

Sem sombra de dúvida, o gênero que mais especula sobre as consequências da tecnociência para a humanidade é a ficção científica. $\mathrm{Na}$ Introdução de The Cambridge Companion to Science Fiction, Farah Men- delsohn (2003) problematiza a ficção científica como (sub)gênero literário, argumentando em favor da mesma como uma discussão ou modo de narrar. Seguindo esta linha de raciocínio, podemos afirmar que há um vasto repertório de obras que, incorporando uma forma hibridizada de ficção especulativa, convoca tanto as convenções e técnicas narrativas da ficção científica quanto as técnicas de gêneros literários mais tradicionais. Jameson (2006, p. 109) analisa esse fenômeno a partir da crise de representação, no capitalismo tardio, argumentando que o romance tradicional se encontra por demais comprometido com o que ele denomina "realismo ontológico". Para ele, o romance tradicional não imagina de maneira adequada o que é significativo, porque o significativo é algo que ainda não existe. $\mathrm{Na}$ visão do crítico marxista, as ficções especulativas têm o potencial para nos fornecer uma espécie de variação experimental de nosso universo empírico. A autora Ursula Le Guin, por sua vez, faz uma comparação entre o romance realista e a obra de ficção científica que lembra muito as distinções feitas por Jameson entre o romance tradicional e as narrativas que incorporam elementos da ficção científica. Ela enfatiza, ainda, o caráter moral e intelectual da ficção científica, e sua preocupação com o coletivo:

\begin{abstract}
Only the trash forms of science fiction are undemanding and predictable; the good stuff, like all good fiction, is not for lazy minds. Where the complexity of realistic novels is moral and psychological, in science fiction it's moral and intellectual; individual character is seldom the key. (LE GUIN, 2011, s/p)
\end{abstract}

Seguindo essa linha de raciocínio, a interface antropoceno ("era dos humanos")/pós-humano mostrase profícua para os estudos de narrativas futurológicas e, em especial, narrativas de catástrofe e "genômicas". Cabe citar Boes e Marshall:

[I] $t$ is worthwhile to reflect on the etymological origins of the term Anthropocene. As many observers have pointed out, the term seems tainted by a certain disingenuousness: it asserts the dominance of man (anthropos) at a time when we have actually become more 
aware than ever of our fungibility as a species. Viewed from a different perspective, however, the term seems perfectly appropriate. For the names of the preceding three geologic epochs - the Pliocene, Pleistocene, and Holocene translate respectively as "newer time," "newest time," and "entirely new time" and thus give these seemingly neutral period designators an inexorable orientation toward the present. By contrast, the term Anthropocene derives from the imaginary etonym anthropos kainos, which we might translate somewhat awkwardly as the "time of the new man." The seeming humanism of the term thus actually reveals its underlying posthumanism. (BOES e MARSHALL, 2014, p. 62)

O termo antropoceno, traz, portanto, um double bind: põe o humano, novamente, no centro, e aponta, a um mesmo tempo, para a época pós-humana, numa espécie de oxímoro, já que, para alguns críticos, o pós -humano antecipa o evento da "Singularidade" - i.e., o futuro pós-biológico da humanidade, geralmente tendo máquinas como nossos descendentes evolucionários. Para outros, como Katherine Hayles (1999), contudo, essa linearidade é problematizada, com nuances mais complexas. Para a autora, o pós-humano não deve ser descrito como uma ruptura apocalíptica com o passado, mas, antes, como uma relação em que inovação e replicação se superpõem - um padrão que ela denomina seriation (seriação), termo que ela toma emprestado da antropologia arqueológica. ${ }^{6}$ Nesse sentido, autoras como Hayles (1999), Ferrando (2012) e Braidotti (2013) usam o conceito como metodologia de revisão crítica do modelo humanista liberal, fruto do Iluminismo, situando-o dentro da prática crítica de repensar/ reconstruir o humanismo. Autores como Neil Badmington (2003) preferem falar em pós-humanismo. Ao optarem pelo emprego de post-humanism, na citação acima, Boes e Marshall vão ao encontro do trabalho desses críticos. Minha própria posição tem sido a de buscar, através da leitura de textos ficcionais, o pós-humanismo crítico assinalado aqui, de perspectiva interdisciplinar, em que o pós-humano figura como reflexão crítica sobre a modernidade tardia, sobretudo no que concerne às novas formas de tecnologia, $\mathrm{e}$ às novas formas de pensamento que lhe são sincrônicas. De que forma as atuais mudanças paradigmáticas trazem, ironicamente, à baila o discurso humanista tradicional, reforçando novas formas de dominação ou exclusão? Que formas de resistência ao discurso tecnológico hegemônico podemos inferir, nas obras de ficção que especulam sobre nosso futuro?

\begin{abstract}
It is a historical fact that the great emancipatory movements of postmodernity are

driven and fuelled by the resurgent "others": the women's rights movement; the anti-racism and decolonization movements; the anti-nuclear and pro-environment movements are the voices of the structural Others of modernity. They inevitably mark the crisis of the former humanist "centre" or dominant subject-position and are not merely anti-humanist, but move beyond it to an altogether novel, posthuman project. (BRAIDOTTI, 2013, p. 37)
\end{abstract}

As palavras de Rosi Braidotti sugerem a produtividade do diálogo entre os projetos pós-humanista e o pós-colonial. Ao mesmo tempo, ao tocar nas questões ambientalistas, ela também traz suas considerações para o tema do antropoceno. Segundo Dipesh Chakrabarty (2009), em seu ensaio bastante citado intitulado "The Climate of History: Four theses", o antropoceno desafia tanto historiadores e críticos pós-coloniais quanto pesquisadores das mais diferentes disciplinas porque nos força a repensar radicalmente o escopo da atuação humana. O historiador indiano escreveu, ainda, em seu conhecido ensaio, que só podemos nos tornar agentes geológicos histórica e coletivamente quando tivermos alcançado números e inventado tecnologias em larga escala a ponto de causar impacto no planeta em si (cf. CHAKRABARTY, 2009, p. 206). Mas como podemos imaginar "em larga escala"? A escala hiperdimensionada é um tropo caro à ficção e ao cinema especulativos. São gêneros que frequentemente dramatizam o momento fatal em que a força antropogênica chega ao limite, "[a] o ponto de virada em que o pano-de-fundo da ação humana, aparentemente lenta e eterna, transforma-se com uma velocidade que só pode significar desastre para os seres humanos"7 (CHAKRABARTY, 2009, p. 205). A ficção especulativa, através da representação de situações limite como catástrofes naturais, epidemias, mutações 
genéticas etc., nos convida a imaginar o momento de risco quando a "antecipação da catástrofe" (BECK, 2007, p. 7) se transforma em perigo e catástrofe de fato - o que é geralmente representado de forma (pós)apocalíptica. Nesse sentido, trata-se de um gênero, ou modo de narrar, que nos ajuda a experimentar, através da imaginação, a força geopolítica que é o humano.

Visando ao diálogo entretecido desses tópicos com os estudos de literatura, convoco quatro obras que abordam de maneira bem definida as questões discutidas acima, centralizando a ação em grupos de pessoas socialmente excluídas, em virtude de experiências ou mutações genéticas ou de alguma pandemia; e/ou navegando por um mundo caracterizado pelo capitalismo desordenado, a decadência ambiental, o colapso radical da ordem, gerando novas formas de exclusão, muitas vezes após uma catástrofe ambiental. Proponho puxar, primeiramente, os fios comuns entre Parable of the Sower, de Octavia Butler (2000) e Oryx and Crake, de Margaret Atwood (2003), buscando, na sequência, aproximações das duas obras com o thriller de hard Science Darwin's Radio, de Greg Bear (1999). Tecerei, por fim, algumas breves comparações/contrastes com The Rag Doll Plagues, do chicano Alejandro Morales (1991). Cabe ressaltar que o argumento para que estas obras sejam agrupadas não é a questão da existência ou não da representação de uma nova era geológica, e sim o valor histórico que o conceito de antropoceno inspira, no sentido de ser um marcador relevante para entabular um debate sobre as intervenções humanas nos sistemas naturais de um modo geral.

Faço, antes, um pequeno desvio, visando a inserir a discussão no escopo mais abrangente do projeto de pesquisa que venho desenvolvendo nos últimos anos. Parece-me que podem ser identificadas duas vertentes de representação em obras que narram a antropo-cena pós-humana: uma apocalíptica e a outra integrada (fica aqui a dívida para com Eco devidamente registrada), na medida em que elas remetem para cenários futurológicos diferentes, até mesmo opostos - cenários que despertam em minha imaginação a tensão entre o que Benjamin R. Barber (1992) chama de "Jihad versus MacMundo": de um lado, a retribalização de uma enorme parcela da humanidade, através de guerras e derrama- mento de sangue - cultura contra cultura, tribo contra tribo, povo contra povo-, em nome da fé, de (ou contra) todo tipo de independência ou autonomia; de outro, a investida de forças econômicas e ecológicas que demandam integração e uniformidade, e a pressão para que as nações formem uma vasta rede comercial global homogênea. Hipótese a ser explorada: a narrativa pós-humana apocalíptica assinala o fim do mundo (pelo menos como o conhecemos) e é, nesse sentido, a representação de um colapso radical da ordem, um pesadelo da anarquia extrema (desaparecimento do Estado). Nessas narrativas, a metrópole aparece como um espaço de inclusão radical. O espaço metropolitano de violência e cacofonia lembra a multidão de Negri (2006), com seu hibridismo e potencial para a subversão de normas. Já na narrativa pós-humana integrada há um aperfeiçoamento sinistro da ordem, um pesadelo do autoritarismo radical (com um Estado fortemente presente e, geralmente, tem-se um estado de polícia). Na primeira, a imagem central é de sucata, com póstecnocratas ensebados, maltrapilhos e, geralmente, nômades, foragidos ou desertores, rondando ou fugindo do mundo, à procura de condições mínimas de sobrevivência. Sua versão de subjetividade é marcada pela "constelação de singularidades" da multidão (HARDT e NEGRI, 2006, p. 60). A segunda representa um mundo clean de corporações predatórias - o que podemos chamar de pesadelo do neoliberalismo aperfeiçoado. Sua versão de subjetividade é marcada pela padronização. Parafraseando Bauman: primeiramente, pela aplicação da racionalidade burocrática aos problemas socioeconômicos, por parte do estado; e segundo, pela constituição de comunidades que opõem "nós" aos "outros", através de políticas xenofóbicas (cf. BAUMAN, 1989, p. 91). Contudo, como buscarei demonstrar, pode ser percebido um deslizamento, nessas obras, entre as duas forças narrativas descritas acima, de difícil resolução, sugerindo que o desenho da sociedade contemporânea é constituído pela tensão contínua entre as duas vertentes, por vezes "confusamente percebidas", para tomar emprestadas as palavras de Milton Santos, na epígrafe acima. Essa "nova desordem do mundo" é descrita por Bauman como o mal-estar na pós-modernidade: 
Após meio século de divisões bem definidas, tanto interesses evidentes como indubitáveis desígnios e estratégias políticas privaram o mundo de estrutura visível e de qualquer - por mais sinistra - lógica. A política dos blocos de poder, que não há muito tempo dominou o mundo, assustado com o caráter horripilante de suas possibilidades: o que quer que venha a the tomar o lugar assusta, no entanto, por sua falta de coerência e direção - e também pela vastidão das possibilidades que pressagia. (BAUMAN, 1998, p. 33)

Entre as obras selecionadas para discussão, as que tematizam os efeitos do antropoceno de forma mais explícita são Parable of the Sower, de Octavia Butler, e Oryx and Crake, de Margaret Atwood. Ambas são ambientadas em sociedades futuristas balcanizadas, onde reina a barbárie, a anarquia, o caos e a guerra diária por alimento e água (cujo preço, na primeira, é mais alto que o da gasolina e, mesmo assim, encontra-se contaminada), tornados escassos devido ao aquecimento global. E ambas representam mundos dominados por corporocracias: em Parable of the Sower - cuja história corresponde ao diário de Lauren Olamina, no período de julho de 2024 a outubro de 2027 - as corporações são donas de cidades inteiras e mantêm seus trabalhadores sob regime de escravidão; em Oryx and Crake o ambiente e seus habitantes são fortemente policiados pela Corporation Security Corps, intimamente aliada à engenharia genética. É interessante de se notar ainda que, tanto na primeira quanto na segunda, há uma separação explícita entre o dentro e o fora: na obra de Butler, sabemos que a protagonista vive no que outrora fora um condomínio fechado (agora em ruínas), e que aventurar-se no mundo "lá fora" é correr risco de vida; e na obra de Atwood os habitantes dos Compounds áreas fechadas, compradas pelas várias empresas para seus membros - são um forte contraste aos Pleeblands, onde vive a "plebe rude", jogada à sua própria sorte, enfrentando perigos e insegurança constantes.

Não obstante o tropo dentro/fora, fica bastante clara a predominância da narrativa apocalíptica, uma vez que, embora ambas as obras representem espaços fechados, onde a ordem fica, supostamente, garantida - na primeira, através do controle dos corpos escravizados dos trabalhadores; e, na segunda, através dos Com- pounds estreitamente vigiados - a presença do estado é apagada, e substituída por corporações. Cabe notar que, em Parable of the Sower, o condomínio fechado, outrora utopia da classe média, já não representa segurança, já que o espaço de "dentro" sofre constantes ataques por parte da multidão - indivíduos desesperados que conseguem entrar às escondidas na comunidade. $\mathrm{O}$ espaço de fora é área de alto risco:

...(it is) risky going outside where things are so dangerous and crazy. (BUTLER, 2000, p. 7). All adults were armed. That's the rule. Go out in a bunch, and go armed. (BUTLER, 2000, p. 8). I think if there were only one or two of us, or if they could not see our guns, they might try to pull us down and steal our bikes, our clothes, our shoes whatever. Then what? Rape? Murder? (BUTLER, 2000, p.10).

Espremido entre o autoritarismo do estado e a tirania empresarial, o sujeito acaba por não conseguir construir uma identidade. "Com a desintegração da estabilidade aparente", escreve Olamina em seu diário, “... as pessoas cedem ao medo e à depressão, à carência e ganância" -

When no influence is strong enough to unite people they divide, they struggle, one against one, group against group, for survival, position, power. They remember old hates and generate new ones, they create chaos and nurture it. They kill and kill and kill.. . . [U]ntil one of them becomes a leader most will follow, or a tyrant most fear. (BUTLER, 2000, p. 91, grifos meus)

Já na obra de Atwood, os cidadãos integrados - i.e, aqueles que internalizam os objetivos, verdades e ética da corporocracia, negando e excluindo qualquer ameaça à padronização - vivem encapsulados nos Compounds. Os Pleeblands, com sua multidão, não são considerados espaços produtivos, porque vivem imersos em revoltas e doenças. Uma outra distinção importante em Oryx and Crake é entre ciência e arte: as artes são desvalorizadas e as ciências são exaltadas como responsáveis por rearrumar os "building blocks of life" do lucro. Esta divisão é simbolizada pelo bem-sucedido tecno- 
crata Crake, e seu melhor amigo, Jimmy (Snowman), que não se considera um bom cientista, mas tem o dom das palavras. O romance, narrado em flashback (ou seja, após a catástrofe), abre com Snowman vivendo no topo de uma árvore, a fim de proteger-se das matilhas de wolvdogs e outras criaturas híbridas. A civilização e o meio-ambiente encontram-se em colapso radical e a antropo-cena é de corpos tóxicos. Snowman sobrevive como pode, evitando os raios solares de um planeta sem camada de ozônio e catando comida em parques de trailers abandonados. Ele cuida, ainda, de um grupo de crianças chamadas de Filhos de Crake. Aos poucos, descobrimos que esses inocentes são o resultado biológico do projeto Paradice, desenvolvido com orçamento milionário de pesquisa e desenvolvimento, e que o mundo geneticamente alterado em que Snowman se encontra é parte de todo o processo. O pesadelo biotecnológico imaginado por Atwood é um olhar crítico, satírico até, sobre a tecnocracia global, liderada por gigantes da indústria farmacêutica cujos nomes são HelthWyzer, OrganInc e RejoovenEsense, que vendem uma variedade de designer drugs e happy pills. Os casais podem encomendar bebês "costumizados" a empresas como Infantade, Foetility e Perfectable. Há, ainda, uma abundância de comidas sintéticas, além de "hiperanimais" criados em laboratório.

Percebemos que, nessas duas obras distópicas, as questões ambientais e político-sociais imbricam-se: as autoras não só representam o colapso ambiental, como mostram-se atentas aos aspectos fascistas da sociedade contemporânea, no sentido de apontarem, em suas ficções especulativas, para os sistemas de poder que geram os controladores da padronização que buscam dominar os cidadãos. À medida que se delineia, em nossa atualidade, um estado policial militarizado que chega para substituir o estado providência (Welfare state) como forma de controle social, a ficção especulativa torna-se, tristemente, realista: é o fascismo mostrando sua cara como possibilidade catastrófica.

Mas vejamos outras formas através das quais as obras sob escrutínio absorvem e dialogam com as causas e consequências da intervenção humana no mundo natural, em especial aquelas que tratam do livre-arbítrio e relações de poder político-corporativas. Em Para- ble of the Sower, a jovem protagonista, Lauren Olamina, sofre da "síndrome da hiperempatia", fazendo com que sinta a dor ou prazer do outro. A síndrome é o resultado do uso, por parte de sua mãe, da smart pill, ${ }^{9}$ durante a gravidez. No mundo pós-apocalipse biotecnológica de Oryx and Crake, de Margaret Atwood, por sua vez, a espécie humana já se encontra modificada por Crake, que mata a antiga espécie, disseminando um vírus contra o qual somente ele está protegido - uma praga de proporções devastadoras, na forma de um "cavalo de Tróia" escondido em uma pílula (ecoando, em certa medida, a smart pill do texto de Butler). De maneira não muito diferente, em Darwin's Radio, de Greg Bear, mulheres grávidas são vítimas de sintomas anômalos entre eles, abortos espontâneos, causados pela ativação de um retrovírus no genoma humano (scattered human endogenous retrovirus activation). As descobertas de um especialista em genoma humano e de uma arqueóloga confluem para um diagnóstico estarrecedor: o SHEVA é o gatilho que irá catapultar a espécie humana para uma nova fase em sua evolução, pois, nas gravidezes virais ${ }^{10}$ subsequentes, as mulheres infectadas com o SHEVA dão à luz crianças mutantes que se comunicam através de uma combinação de olfaction, double-speak e curiosas pintas epidérmicas "empáticas" (ecoando, em grande medida, a síndrome da empatia de Olamina, em Parable of the Sower).

A obra de Bear constitui o que Lockhurst (2007) denomina evolutionary catastrophism - a tematização da alteração biotecnológica da espécie humana e suas implicações biopolíticas. A leitura que o crítico faz da representação da catástrofe nas ficções de Bear traz um elemento interessante para a presente discussão, pela sua argumentação de que o catastrophism estaria inscrito na imaginação estadunidense, desde a visão apocalíptica dos puritanos, e que sua reimaginação pelo autor serve como uma espécie de história alternativa do estado:

Bear elaborates a complex social portrait of species change. This story is overdetermined by weaving together government security agencies, Senate hearings, journalistic scoops, scientific conferences, anthropologists in difficult disputes over artefacts in Native American territories, private drug companies competing for patents, 
disease control agencies, and the pressure of the evangelical Christian right. (LOCKHURST, 2007, p. 216)

A antropo-cena descrita acima aponta tanto para o macmundo corporativo e midiático estadunidense como para seu fundamentalismo. Lockhurst lembra as "Darwin wars" - a batalha entre o darwinismo e o criacionismo -, que ganharam ímpeto na década de 1980, e seguem sendo ponto de contenda, à medida que o poder da direita evangélica estende, progressivamente, seus tentáculos para o estado. ${ }^{11}$

Darwin's Radio emaranha o fundamentalismo religioso - uma parcela dos cidadãos afirma que as mulheres contaminadas com o Herod's flu (o nome em si traz conotações bíblicas) estão povoando o mundo com os filhos do demônio - com o biopoder. Para Gilles Kepel (apud BAUMAN, 1998, p. 226), "[c]omo os movimentos dos trabalhadores no passado recente, os movimentos religiosos de hoje têm uma capacidade singular de revelar os males da sociedade, sobre os quais eles têm seu próprio diagnóstico”. Bauman (1998, p. 228) acrescenta às considerações de Kepel que "o fascínio do fundamentalismo provém de sua promessa de emancipar os convertidos das agonias da escolha. Aí a pessoa encontra, finalmente, a autoridade indubitavelmente suprema, uma autoridade para acabar com todas as outras autoridades" (grifo de Bauman). De acordo com a conceituação de Foucault (1988), o biopoder consiste em estratégias de intervenção sobre a existência coletiva em nome da vida e da morte. Na janela que Bear abre para um futuro iminente, o governo federal dos EUA, em parceria com cientistas integrados, após, primeiramente, se negar a divulgar a verdade sobre o Herod's flu para a população, passa a pressionar os pais a entregarem seus filhos mutantes para o governo. Se o fundamentalismo é um mecanismo de poder que oblitera o livre-arbítrio e o livre-pensar, deixando-os em mãos de uma autoridade religiosa, o biopoder é, literalmente, o poder do estado sobre os corpos - uma série de mecanismos reguladores

inicialmente endereçad[o]s a populações que poderiam ou não ser territorializadas em termos de nação, sociedade ou comunidades pré-dadas, mas que também poderiam ser especificad[o] $s$ em termos de coletividades biossociais emergentes, algumas vezes especificadas em termos de categorias de raça, etnicidade, gênero ou religião, como nas formas recentemente surgidas de cidadania genética ou biológica. (RABINOW, 2006, p. 29, grifos meus)

São práticas, em nome da saúde pública, que, no contexto de Darwin's Radio, servem para esconder a ligação entre o SHEVA e a evolução humana. A repressão do estado, configurando a mutação como uma doença, é uma alusão a questões candentes, na contemporaneidade - alianças entre governos e a indústria biotecnológica, ética médica e da pesquisa científica, direito ao aborto, testes em laboratório. A aliança entre a força-tarefa e a empresa biotecnológica Americol sintetiza os problemas inerentes ao que um dos personagens descreve como "...the big world of cash biology, so importante and secret and full of itself" (BEAR, 1999, p. 73). O grande segredo, e a conspiração para abafá-lo, é a ligação entre o passado da humanidade (representado pela figura dos arqueólogos) e seu futuro (representado pelos cientistas): o vírus, adormecido em nossos genes por milhões de anos, é ativado e ameaça concepções tradicionais de humano.

Vemos como o tema da contaminação está ligado ao pânico relacionado às epidemias. Ao mesmo tempo, a "evolução viral", em Darwin's Radio, serve de alegoria para o temor da mudança social - que desagua na exclusão do diferente e, por extensão, da xenofobia. Podemos estabelecer, ainda, um paralelo com o temor às epidemias atuais de dengue, zika e chicungunha, frequentemente atribuídas à contaminação do mundo hegemônico pelo "terceiro mundo". Sobretudo no caso do zika vírus, que, diferentemente do vírus da dengue e do chikungunya, também transmitidos pelo mesmo veículo - o mosquito aedes egypti -, invade o sistema neurológico e reprodutor feminino, causando microcefalia em fetos e recém-nascidos e Síndrome de Guillain-Barré (SGB), que afeta o sistema nervoso e causa fraqueza muscular. A questão atinente à modificação genética induzida pelo vírus no feto contaminado permanece um mistério, e há, como em Darwin's Radio, preconceito contra as mães contaminadas. ${ }^{12}$

O tema do contágio também surge na obra The Rag 
Doll Plagues, de Alejandro Morales, que, no último episódio hiperdimensiona a catástrofe através de tropos de contaminação em cenários transnacionais (Los Angeles/ Cidade do México), que funcionam como metáforas centrais para trazer à tona questões como biopoder, diferentes respostas culturais à contaminação do corpo e as consequências da superpopulação (sendo as cidades mencionadas acima paradigmáticas, como sabemos). A obra apresenta três histórias interligadas, sobre médicos lutando contra doenças infecciosas, passadas em três épocas distintas: no México colonial; no México e sul da Califórnia dos dias presentes; e na tecnocrática LaMex (outrora EUA, Canadá e México) de 2079, em que a Tríplice Aliança reina suprema. $\mathrm{O}$ primeiro episódio narra a história de um médico espanhol, enviado ao México para diagnosticar e curar a praga la mona - um vírus mutante trazido pelos espanhóis para as colônias americanas com o intuito de dizimar a população indígena, e que se volta contra os colonos; o segundo episódio é narrado por um médico do século XX, residente em Los Angeles, cuja mulher hemofílica contrai AIDS, através de uma transfusão de sangue; na segunda terceira história, narrada pelo neto do médico do episódio anterior, uma praga semelhante à la mona (traduzida para the rag doll plagues) está aniquilando a população de LaMex.

O poder de resistência da nova praga rag doll reside exatamente em sua natureza transitória, capacidade de adaptação e inteligência artificial. Para efeitos da discussão que está sendo entabulada, focarei apenas no terceiro episódio, ou era, do romance de Morales. Os agentes do regime biopolítico que controla LaMex lutam contra uma epidemia que ameaça a população de Los Angeles. Embora o câncer e a AIDS tenham sido erradicados, surge uma nova "praga", resultante da extrema poluição ambiental e da superpopulação, que não discrimina suas vítimas por raça, classe ou gênero. Infectados com uma doença pulmonar, os cidadãos morrem afogados em seu próprio sangue, pois a doença causa o colapso respiratório. $\mathrm{O}$ médico que narra o episódio, Gregory, descobre, por acaso, que a população da Cidade do México - uma das cidades mais poluídas do mundo - é imune à praga, por conta das mutações genéticas em seu sangue que lhe possibilita adaptar-se e sobreviver ao ambiente infectado. Vemos que, apesar da representação de uma era pós-nacionalista, a depleção dos recursos mexicanos por parte da cultura hegemônica continua sendo a práxis no futuro imaginado por Morales: os mexicanos, outrora migrantes indocumentados servindo de mão-de-obra barata para os estadunidenses, continuam "dando seu sangue" - só que agora, ironicamente, como cobiçados doadores do sangue que irá salvar o "primeiro mundo" da devastação.

As tensas relações entre "anglos" e mexicanos estão subjacentes à narrativa de The Rag Doll Plagues, trazendo o tema das epidemias para um contexto pós-colonial, na medida em que a experiência de chicanos é marcada por várias características do colonialismo, tais como exploração econômica e opressão política, podendo ser adotado o conceito de colonialismo interno para referir-se à subordinação socioeconômica e cultural de migrantes mexicanos na sociedade estadunidense.

\section{Conclusão}

Ao privilegiar obras de ficção especulativa que se encontram polinizadas por temas biotecnológicos, e cujos enredos representam a tensão entre uma vertente narrativa "apocalíptica" e outra "integrada", busquei situar e valorizar a representação da cena humana em cada uma delas, apontando situações em que os personagens lutam (reiteradamente sem sucesso) ora contra danos ecológicos, ora contra a alienação reificante a que são submetidos pelo biopoder e pela biopolítica. Cabe observar que as obras em que predomina a vertente (pós) apocalíptica - marcadamente, The Parable of the Sower, de Octavia Butler, e Oryx and Crake, de Margaret Atwood - adequam-se à categoria de distopia crítica, associada ao trabalho de Raffaella Baccolini e Tom Moylan (2003), que co-organizaram uma coletânea importante, intitulada Dark Horizons: Science Fiction and the Dystopian Imagination. Em Scraps of the Untainted Sky, Moylan (2000) escreveu que, após a utopia engajada dos anos 1970 e a contrapelo do impulso para o desespero dos anos 1980, muitos autores de ficção científica voltaram-se para a distopia como forma de representar a realidade social de seu tempo. Ele remete-se à definição de Baccolini de distopias críticas como obras que "mantêm um âmago utópico", ajudando, ao mesmo 
tempo, a "desconstruir a tradição e a reconstruir alternativas" (cf. MOYLAN, 2000, p. 188). Em The Parable of the Sower, o âmago utópico de que fala Baccolini tem cunho religioso: o projeto "Earthseed" sonhado/ inaugurado por Olamina, uma fé que preconiza "Deus é mudança”. Ao final de uma longa jornada, Olamina e seus seguidores encontram uma comunidade utópica rural, ao norte da Califórnia, chamada Acorn. ${ }^{13}$ Já em Oryx and Crake, o âmago utópico é frágil e ambíguo, porque não fica claro se os Filhos de Crake, por ora destituídos de linguagem, poderão um dia vir a ser considerados uma versão 1.1. do humano. Mas há que se considerar ainda a "hiperempatia" de Olamina e as pintas "empáticas" dos mutantes em Darwin's Radio, de Greg Bear, como possíveis elementos utópicos. Existe uma preocupação crescente com o declínio da empatia no mundo atual - geralmente atribuído à falta de laços comunitários e de relações face-a-face. ${ }^{14}$ Já existem, inclusive, programas dedicados a ativar e empatia, visando a evitar bullying nas escolas, violência doméstica etc. ${ }^{15}$ Em ambas as obras, a evolução humana caminharia para uma espécie mais empática e, portanto, mais humanizada - embora, a de Bear, mais "integrada" (com um estado fortemente presente, como vimos), aponte para o genocídio e estancamento dessa evolução. Já The Rag Doll Plagues, de Alejandro Morales, se insere na prática cultural chicana de tornar visíveis, através de elementos de ficção científica empregados como metáforas, experiências de marginalização ${ }^{16}$, lembrando o "Chicanafuturism" de Catherine Ramirez, que "questiona as promessas da ciência, tecnologia e humanismo para chicanas, chicanos e outros sujeitos de cor" e "reflete histórias coloniais e pós-coloniais de indigenismo, mestizaje e sobrevivência" nas Américas (RAMIREZ, 2008, p. 187).

Vemos, então, que, apesar do cunho futurológico, essas obras não ignoram ou descartam as forças sociais que assolam o mundo contemporâneo, como o mercado de capital global e decisões/alianças políticas opacas. Abre-se, através da leitura das mesmas, uma boa ocasião para explorar as fontes discursivas - ambientais, biológicas, políticas, literárias, culturais e sociológicas, entre outras - que contribuem para um novo elenco de desafios teóricos e disciplinares.
Embora o objetivo deste ensaio não tenha sido o de fazer ecocrítica estrito senso, as ficções especulativas discutidas aqui conduzem a reflexões situadas dentro do debate ecocrítico ou "crítica climática"17: pela forma como alertam para o aquecimento global e para a iminência da escassez de recursos naturais; mas, sobretudo, pela forma como salientam a dependência ecológica da humanidade e nosso caráter transitório, e transformam a mudança evolucionária em um problema coletivo. Partindo do conceito de antropoceno como chave de leitura, busquei discutir como as antropo-cenas representadas nas ficções especulativas discutidas aqui esbarram em um amplo escopo de questões, e em questões de amplo escopo, como as que Latour delineia abaixo:

\section{[...] this new concept [Anthropocene] defines the human agency by drawing on a bewildering range of entities, some clearly related to the "natural" sciences - biochemistry, DNA, evolutionary trends, rock formation, ecosystem - while others clearly relate to what ethnographers have learned to register throughout their field work - patterns of land use, migrations of plants, animal and people, city life, trajectory of epidemics, demography, inequalities, classes and state policies. (LATOUR, 2014, 139-AAA 3)}

Dessa maneira, foi de relevância incontornável entremear essa reflexão com a discussão dos conceitos de biopoder e biopolítica, visando a fortalecer o argumento de que tais conceitos são inextricáveis, na "era dos humanos".

\section{Notas}

1. A época mais recente do período quaternário. Grosso modo, um todo/uma totalidade [holo] recente.

2. O termo foi cunhado pelo biólogo Eugene F. Stoermer, mas Crutzen o reinventou e popularizou. Segundo o próprio Stoermer, ele começou a empregar o termo "antropoceno" na década de 1980, mas nunca o havia formalizado até ser contatado por Paul Crutzen. (cf. STEFFEN et al, 2011, p. 843)

3. O início do Antropoceno ainda é alvo de contenda. Algumas datas sugeridas incluem a invenção da máquina a vapor, por James Watts, em 1784, a emissão de radiação provocada por testes nucleares, na década 
de 1950, e até mesmo o início das atividades agrícolas, há mais de dez mil anos.

4. A título de ilustração: o termo aparece em cerca de 200 artigos publicados em periódicos revisados por pares, é título de um periódico acadêmico e é o foco de estudo do grupo do IUGS, e agora do WGA, citados acima.

5. Refiro-me, aqui, às narrativas envolvendo experiências genéticas - ou mutações genéticas resultantes de evolução, alterações no meio-ambiente, contaminações etc.

6. $\mathrm{Na}$ antropologia arqueológica, é comum fazer-se o mapeamento das mudanças nos atributos de artefatos, através de quadros de seriação. Alguns atributos mudam de um modelo para o outro, enquanto que outros permanecem iguais. Esta técnica serial revela padrões de inovação e replicação - como, por exemplo, no caso da mudança da lamparina para a lâmpada, em que o pavio é substituído pelo filamento, mantendo a mesma função, qual seja, de iluminar. Hayles estrutura os capítulos de seu livro How We Became Posthuman como um serial chart, mapeando a história da cibernética desde a década de 1950.

7. Trad. livre de "... a tipping point at which this slow and apparently timeless backdrop for human actions transforms itself with a speed that can only spell disaster for human beings."

8. Trad. livre de "When apparent stability disintegrates [...] people tend to give in to fear and depression, to need and greed."

9. Trata-se de uma droga estimulante prescrevida para pessoas com desordens do sono, e que, supostamente, estimula as funções cognitivas. Remeto o leitor à matéria “Nootrópicos, as 'drogas inteligentes' que são moda no Vale do Silício", de Jaime González, publicada no jornal O Globo [online], seção Ciência e Saúde, 27 de jul. de 2015.

10. Uma vez infectadas, as mulheres abortam da primeira gravidez, passando a dar à luz (sem relações sexuais) aos filhos do Herod's flu (como a gravidez viral passa a ser conhecida).

11. Um fenômeno semelhante pode ser constatada no Brasil, com o crescimento da "bancada evangélica" no congresso, nos últimos anos. A mistura de política e religião é a marca da atuação dos pastores deputados da Frente Parlamentar Evangélica (FPE), encabeçada pelo deputado e pastor João Campos, autor do projeto de lei (PL 6.583/2013), que, entre outros itens, reconhece a família apenas como uma entidade heteronormativa. Cf. a reportagem pública "Os pastores do congresso". Ver, tb., a tese de doutorado de Bruna Suruagy do Amaral Dantas "Religião e política: ideologia e ação da 'Bancada Evangélica' na Câmara Federal', em que ela entrevista parlamentares da bancada evangélica, de 2007 a 2011, assessores e jornalistas.

12. Ver o artigo "O Zica e o Risco da Pandemia do Preconceito”, de Luís Nassif, no jornal GGN [online], onde o jornalista discute a "dupla violência contra os direitos das mulheres e das pessoas com deficiência".

13. Nos romances subsequentes de Butler, conhecidos como Earthseed novels, o projeto estende-se para a emigração para outros planetas, confirmando a filosofia do Earthseed de que é necessário estar sempre em mudança, movimento.

14. A empatia é geralmente considerada um construto cognitivo - i.e., que depende de uma relação especular com o outro, da observação de suas reações corporais, expressões faciais etc., mas a maioria dos especialistas concorda que tem um forte componente emocional e neural.

15. Cf. a organização Roots of Empathy, no endereço http://rootsofempathy.org

16. Remeto o leitor à performance "Chicano Cyber Punk", do conhecido artista chicano Guillermo Gómez-Peña.

17. O livro de Adam Trexler Anthropocene Fictions: The novel in a time of climate change privilegia o gênero "cli-fi" (climate fiction) e discute, entre outras, as obras Oryx and Crake e The Year of the Flood de Atwood.

\section{Referências}

ATWOOD, Margaret. Oryx and Crake. Edição Kindle [Amazon] 1. ed. London: Bloomsbury, 2003.

BACCOLINI, Raffaella; MOYLAN, Tom, orgs. Dark Horizons: Science fiction and the dystopian imagination. London/New York: Routledge, 2003.

BADMINGTON, Neil. “Theorizing Posthumanism”. Cultural Critique, n. 53, Posthumanism, [Winter] 2003, p. 10-27.

BAIMA, Cesar. Cientistas acreditam que planeta está em nova era geológica: o Antropoceno. O Globo [online], 08 jan. 2016. Disp: <http://oglobo.globo. com/sociedade/ciencia/cientistas-acreditam-queplaneta-esta-em-nova-era-geologica-antropoceno18431630\#ixzz3zZmrbVe0>. Último acesso em 01.08 .2016

BARBER, "Jihad vs. McWorld”. The Atlantic, Mar. 1992. Disponível: http://www.theatlantic.com/magazine/ archive/1992/03/jihad-vs-mcworld/3882/\#. Último acesso em 12.03.2013.

BAUMAN, Zygmunt. O mal-estar na pós-modernidade. Trad. Mauro Gama e Cláudia Martinelli Gama. Rev. 
técnica Luís Carlos Fridman. Rio de Janeiro: Zahar, 1998.

BEAR, Darwin's Radio. Norwalk, CT: Easton Press, 1999.

BECK, Ulrich. World at PRisk. Risk Cambridge: Polity Press, 2007.

BLANCHOT, Maurice. The Writing of the Disaster. Trad. Ann Smock. U of Nebraska P, 1995. 1. ed. 1986. 1. ed. em francês L'écriture du désastre. Paris: Gallimard, 1980.

BOES, Tobias; MARSHALL, Kate. "Writing the Anthropocene. An Introduction". Minnesota Review, v. 83, p. 60-72, 2014.

BRAIDOTTI. Rosi. The Posthuman. Cambridge: Polity Press, 2013.

BUTLER, Octavia. Parable of the Sower. New York: Warner Books, 2000.

CARRINGTON, Damian. “The Anthropocene Epoch: Scientists Declare Dawn of Human-Influenced Age" The Guardian [online]. 29 ago. 2016, s/p.

CHAKRABARTY, Dipesh. The Climate of History: Four theses. Critical Inquiry, v. 35, p. 197-222, 2009.

DANTAS, Bruna Suruagy do Amaral. Religião e política: ideologia e ação da Bancada Evangélica na Câmara Federal. Tese de doutorado. PUC-SP, PPG em Psicologia Social, 2011.

FERRANDO, Francesca. "The Party of the Anthropocene: Posthumanism, Environmentalism and the Postanthropocentric Paradigm Shift". Relations [online], v. 42, p. 159-173, nov. 2016. Disp. https://www.researchgate.net/ publication/310581120_The_Party_of_the Anthropocene_Post-humanism_Environmentalism_ and_the_Post-anthropocentric_Paradigm_ Shift. Acesso em 2 nov. 2016.

FOUCAULT, Michel. História da Sexualidade, v. 1: a vontade de saber. Rio de Janeiro: Edições Graal, 1988.

GEYER, Michael; BRIGHT, Charles. "World History in a Global Age". The American Historical Review, v. 100, n. 4, p. 1034-1060, 1995.

GÓMEZ-PEÑA, Guillermo. "Chicano Cyber Punk" [performance gravada ao vivo]. Disp. https://www. youtube.com/watch?v=QoH9sBRrVr4 Último acesso em 30.10.2016.

GONZÁLEZ, Jaime. Nootrópicos, as 'drogas inteligentes' que são moda no Vale do Silício. O Globo [online], seção Ciência e Saúde, 27 jul. 2015. Disp: <http://g1.globo. com/ciencia-e-saude/noticia/2015/07/nootropicos-asdrogas-inteligentes-que-sao-moda-no-vale-do-silicio. html>. Último acesso em 14.06.2016.
HARDT, Michael; NEGRI, Antonio. Multitude: War and Democracy in the age of empire. New York \& London: Penguin, 2006.

HAYLES, Katherine N. How We Became Posthuman: Virtual bodies in cybernetics, literature and informatics. Chicago: Chicago UP, 1999.

JAMES, Edward; MENDLESOHN, Farah, eds. The Cambridge Companion to Science Fiction, Cambridge: Cambridge UP, 2003.

JAMESON, Fredric. “The Experiments of Time: Providence and Realism”. In: MORETTI, Franco, org. The Novel, v. 2. Princeton: Princeton UP, 2006, p. 95-127.

LATOUR, Bruno. Anthropology at the Time of the Anthropocene - a personal view of what is to be studied. American Association of Anthropologists, Washington, Dec. 2014 (draft for comments). Disp: $<$ www.bruno-latour.fr/sites/default/files/139-AAAWashington $>$. PDF baixado do site em 22.05.2016.

LE GUIN, Ursula. "This sophisticated novel addresses who we are" - review of Embassytown by China Miéville. The Guardian, Sat. 7 May, 2011. Disp: <http://www. guardian.co.uk/books/2011/may/08/embassytownchina-mieville-review $>$ Último acesso em 24.10.2016

LOCKHURST, Roger. "Catastrophism, American style: the fiction of Greg Bear". Yearbook of English Studies, v.37, n.2, p. 215- 233, 2007.

MORALES, Alejandro. The Rag Doll Plagues. Houston: Arte Público Press, 1991.

MOYLAN, Tom. Scraps of the Untainted Sky: Science fiction, utopia, dystopia. Boulder: Westview Press, 2000.

NASSIF, Luís. O Zica e o Risco da Pandemia do Preconceito. GGN - o jornal de todos os Brasis,

03/02/2016. Disp. <http://jornalggn.com.br/noticia/ozica-e-o-risco-da-pandemia-do-preconceito $>$. Último acesso em 28.10.2016.

PUBLICA; agência de reportagem e jornalismo investigativo. Os pastores do congresso. Disp: <http:// apublica.org/2015/10/os-pastores-do-congresso/> Último acesso em 24.10.2016

RABINOW, Paul; ROSE, Nikolas. O conceito de biopoder hoje. Trad. Aécio Amaral Jr. Política \& Trabalho: revista de ciências sociais, n. 24, p. 27-57, 2006.

RAMÍREZ, Catherine. "Afrofuturism/Chicanafuturism: Fictive Kin.” Aztlán: A Journal of Chicano Studies, v. 30, n. 1, p. 185-194, 2008.

SANTOS, Milton. Por uma outra globalização: do pensamento único à consciência universal. Rio de Janeiro: Record, 2011. 
STEFFEN, Will et al. The Anthropocene: conceptual and historical perspectives. Philosophical Transactions of the Royal Society A, n. 369, p. 842-867, 2011. doi:10.1098/rsta.2010.0327. Disp: <http://rsta. royalsocietypublishing.org $>$ PDF baixado do site da Royal Society em 29.03.2016.

TREXLER, Adam. Anthropocene Fictions: The novel in a time of climate change. Charlottesville\London: $U$ of Virginia P, 2015.

ZALASIEWICZ, Jan et al. Are We Now Living in the Anthropocene? GSA Today, v. 18, n. 2, p. 4-8, Fev. 2008. doi: 10.1130/GSAT01802A.1

Recebido em: 01/11/2016 Aceito em: 10/02/2017 